\title{
Impact of agr dysfunction on virulence profiles and infections associated with a novel methicillin-resistant Staphylococcus aureus (MRSA) variant of the lineage ST1-SCCmec IV
}

Fabienne Antunes Ferreira', Raquel Rodrigues Souza' ${ }^{1}$ Bruno de Sousa Moraes', Ana Maria de Amorim Ferreira², Marco Antônio Américo', Sérgio Eduardo Longo Fracalanzza', José Nelson dos Santos Silva Couceiro ${ }^{1}$ and Agnes Marie Sá Figueiredo ${ }^{1^{*}}$

\begin{abstract}
Background: A novel variant of the ST1-SCCmedV methicillin-resistant Staphylococcus aureus (MRSA) lineage, mostly associated with nosocomial bloodstream infections (BSI), has emerged in Rio de Janeiro. Bacterial biofilm has been considered a major virulence factor in central venous catheter-associated BSI. The mechanisms involved in biofilm formation/accumulation are multifactorial and complex. Studies have suggested that biofilm production was affected in vitro and vivo for agr-null mutants of $S$. aureus.

Results: The impact of naturally occurring inhibition of agr signaling on virulence profiles and infections associated with the ST1 variant was investigated. agr dysfunction was detected in a significant percentage (13\%) of the isolates with concomitant increase in biofilm accumulation in vitro and in vivo, and enhanced ability to adhere to and invade airway cells. The biofilm formed by these ST1 isolates was ica-independent and proteinaceous in nature. In fact, the improved colonization properties were paralleled by an increased expression of the biofilm-associated genes $f n b A$, spa and sasG. The transcription of sarA, a positive regulator of agr, was two-times reduced for the agr-dysfunctional MRSA. Remarkably, the agr inhibition was genetically stable. Indeed, agr-dysfunctional isolates succeed to colonize and cause both acute and chronic infections in hospitalized patients, and also to effectively accumulate biofilm in a mouse subcutaneous catheter implant model.

Conclusion: The ability of agr-dysfunctional isolates to cause infections in humans and to form biofilm in the animal model suggests that therapeutic approaches based on agr-inactivation strategies are unlikely to be effective in controlling human-device infections caused by ST1 isolates. The increased biofilm accumulation associated with the acquisition of multiple antimicrobial resistant traits might have influenced (at least in part) the expansion of this USA400 related clone in our hospitals.
\end{abstract}

Keywords: MRSA, ST1-SCCmecIV, USA400, agr, Biofilm, Virulence factors

\footnotetext{
* Correspondence: agnes@micro.ufrj.br

1Departamento de Microbiologia Médica, Instituto de Microbiologia Paulo de Góes, Universidade Federal do Rio de Janeiro, Rio de Janeiro, RJ, Brazil

Full list of author information is available at the end of the article
} 


\section{Background}

Community-acquired methicillin-resistant Staphylococcus aureus (CA-MRSA) lineage ST1- SCCmec IV was first reported in the 1980s among aborigines in Australia (WA-1 clone) and in the USA (MW2/USA400 clone) where cases of fatal infections were reported in Michigan, Minnesota and North Dakota [1-3]. Nowadays, CA-MRSA infections have been described in different countries involving a number of genetically distinct lineages $[4,5]$.

Many CA-MRSA isolates (including USA300, USA400 and USA1100) carry lukSF encoding for Panton-Valentine leukocidin (PVL). Despite the controversy regarding the role of the PVL, this leukocidin has been linked to severe skin infections and necrotizing pneumonia [6-8]. In the USA, USA300 has replaced USA400 as the predominant clone in many communities [9]. However, USA400 isolates were the main cause of an outbreak of skin infections that occurred in rural southwestern Alaska, in 1996-2000 [10]. Indeed, USA400 was the far most common CA-MRSA clone recovered from three northern remote communities of Saskatchewan, Canada [11]. In 2005, a novel variant of the lineage ST1-SCCmecIV emerged in Rio de Janeiro city as an important cause of bloodstream infections (BSI) [12]. It is intriguing that despite the genetic relationship with Australian WA-1 and MW2/USA400, isolates of this novel clone were PVL-negative, multiresistant and mostly involved in hospital-associated BSI [12]. It is still poorly understood why isolates of CA-MRSA have become successful so quickly [13]. Nevertheless, for hospital-associated MRSA (HA-MRSA), the bacterial ability to produce biofilm has been recognized as an important virulence factor for the pathogenesis of intravenous catheter-related bacteremia and infections associated with the use of medical prosthesis. In addition, the bacterial ability to adhere to, colonize and invade host tissues is considered important factor associated with bacterial virulence, adaptation and spread [14,15]. Different surface proteins have been implicated in biofilm formation/accumulation and host colonization, including fibronectin-binding proteins A and B (FnBPAB), S. aureus surface protein $\mathrm{G}$ (SasG) and staphylococcal protein A (Spa) [16-19]. In addition, extracellular DNA (eDNA) has also been associated with bacterial biofilms [20].

It is also well known that virulence in $S$. aureus is modulated by an intricate regulatory network [21]. The accessory gene regulator (agr), the major S. aureus quorum sensing system, down-regulates a number of genes encoding for cell-surface proteins involved in colonization processes, and up-regulates (by an indirect mechanism involving RNAIII dependent down-regulation of Rot) different exoproteins associated with host-cell damages [22]. Previous works have suggested that inactivation of Agr could be very effective at inhibiting $S$. aureus infections [23], including those associated with implantable medical devices $[24,25]$. Studies have demonstrated that biofilm production, host cell adhesion and invasion as well as other mechanisms involved in the establishment and course of staphylococcal diseases were affected by knockout of the agr locus [26-28]. Despite the improvements achieved in staphylococcal virulence, most of the investigations have been carried out using relatively few laboratory constructions or clinical isolates [28]. In addition, those results have not been validated using current clinical isolates of MRSA. In this paper we characterized the biofilm formed by USA400-related (ST1-SCCmecIV) MRSA emergent in Rio de Janeiro, investigated the adhesive and invasive properties of naturally agr-dysfunctional isolates and analyzed the impact of the agr inhibition on S. aureus infections associated with the use of medical device. Our results suggest that strategies based on agr inactivation approaches may not be effective as an anti-biofilm strategy in the management of device-associated infections caused by these MRSA isolates.

\section{Results \\ Biofilm}

All sixty ST1 isolates tested were able to produce biofilm on inert surfaces. The majority ( $58.3 \%$ and $25 \%$; respectively) exhibited a moderate (BU varying from 0.468 to 0.901 ) or strong (BU varying from 1.008 to 3.615 ) biofilm phenotypes (Figure 1, top). For 19 randomly selected isolates, the ability to accumulate biofilm on human Fn-coated surfaces increased significantly $(p<0.01$ to $p<0.0001)$ when compared with that on inert surfaces (Figure 1, bottom).

\section{Proteinaceous nature of the biofilm}

Treatment with proteinase K virtually disrupted preformed biofilms for 12 ST1 isolates tested. However, the carbohydrate oxidant metaperiodate almost did not affect the biofilm accumulated by these isolates (Figure 2, top). CLSM studies revealed that the agr-dysfunctional 08-008 accumulated a denser and compact biofilm when compared to the heterogeneous film formed by the agr-functional isolate (96/05). Despite the stronger biofilm phenotype displayed by the isolate $08-008$, proteinase $\mathrm{K}$ could significantly remove the biological film accumulated (Figure 2, bottom).

\section{Role of eDNA in ST1 biofilm}

No correlation was detected between the activity of bacterial DNase and the levels of biofilm accumulated by 17 USA400-related isolates displaying strong, moderate or weak biofilm phenotypes (Figure 3, top). The addition of $28 \mathrm{U} /$ well DNase I in the culture media did not significantly affect the biofilm formed by these ST1 isolates. However, when this concentration was increased to $56 \mathrm{U} /$ well, a significant $(\mathrm{p}=0.0078)$ reduction of $31 \%$ in biofilm accumulation was detected (BU untreated $=0.91 \pm 0.1$ and treated $=0.63 \pm 0.078$; Figure 3, left bottom). In addition, the concentration of eDNA recovered from the supernatant of 

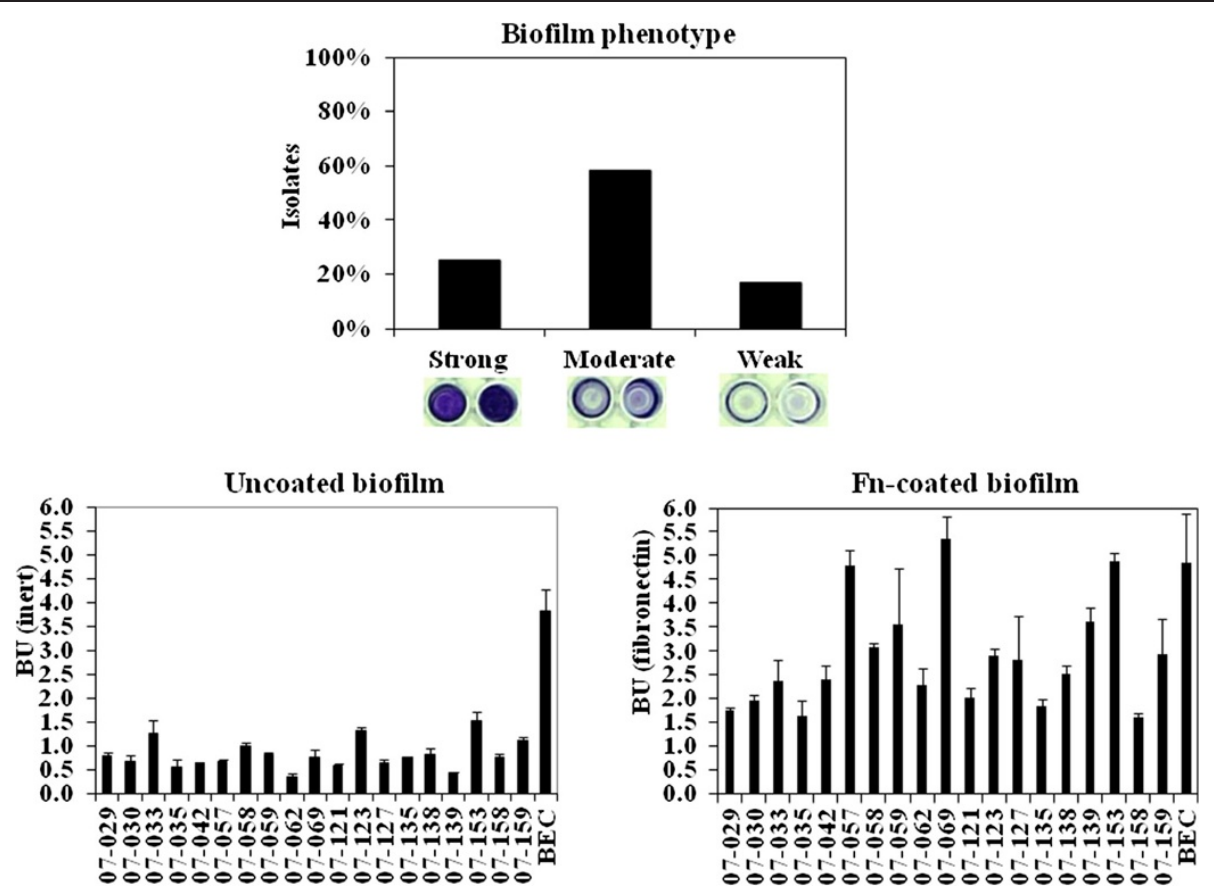

Figure 1 Biofilm formed by ST1 isolates. Top: Percentage of the total 60 ST1 isolates displaying strong, moderate and weak biofilm phenotypes. Wells show the different biofilm phenotypes formed on inert polystyrene surfaces by representative ST1 isolates. Bottom: Biofilm formed on inert or fibronectin-coated surfaces by 19 ST1 isolates.

the strong biofilm producer $(\mathrm{BU}=1.167 \pm 0.07)$ isolate 08-008 was $182 \mathrm{ng} / \mathrm{mL}$, three-times higher than that determined for the weaker producer $(\mathrm{BU}=0.348 \pm 0.01$ ) isolate 117/05 (Figure 3, right bottom). In agreement with these results, we have also detected a moderate correlation $(\mathrm{r}=0.59)$ between bacterial autolysis and biofilm accumulation, when 4 stronger biofilm producers were compared with the same number of weaker producers (Figure 4).

\section{agrRNAIII inhibition}

About 13\% (8/60) of the USA400 related isolates exhibited no apparent hemolytic activity (Figure 5 , top right). These 8 isolates had almost undetectable agr expression by RT-qPCR (Figure 5, top left). Of significance is the fact that 4 out of 8 agr-dysfunctional MRSA were recovered from BSI (50\%). The RNAIII transcriptional levels for the 8 agr-functional isolates analyzed were significantly lower than that of strain RN6390B (Figure 5, top left). When we correlated the biofilm values (BU) with the levels of RNAIII transcription, we found that the population of clinical isolates with no hemolytic activity showed significant increase $(p=0.01)$ in biofilm formation/accumulation (Figure 5, bottom). No significant difference could be detected in the values of oxacillin MIC when $a g r$-functional $\left(\mathrm{MIC}_{90}=128 \mu \mathrm{g} / \mathrm{mL}\right)$ were compared with agr-dysfunctional isolates $\left(\mathrm{MIC}_{90}=128 \mu \mathrm{g} / \mathrm{mL}\right)$. Indeed, when we quantified $m e c A$ transcripts for $5 \mathrm{ST} 1$ isolates, $08-008(\mathrm{RQ}=0.06 \pm$
0.004), 89/05 (RQ=1.194 \pm 0.1$), 08-068 \quad(\mathrm{RQ}=2.841 \pm 0.816)$, $07-135(\mathrm{RQ}=1.867 \pm 0.69), 07-058(\mathrm{RQ}=1 \pm 0.62)$, displaying different levels of agr expression (Figure 5, top left), we could not find a negative linear correlation between mecA and agr expressions (correlation coefficient, $\mathrm{r}=0.823$ ). Thus, an overexpression of $m e c A$ can not to be implicated in the inhibition of RNAIII transcription. Because agr is positively regulated by SarA, the expression of sarA gene was also analyzed by RT-qPCR. Our data showed a significant $(p=0.0052)$ attenuation of sarA for the agrdysfunctional isolate 08-008 when compared with the $a g r$-functional 96/05 (Figure 6).

\section{Animal model}

The naturally agr-dysfunctional MRSA was able to colonize and grow on the surface of implanted catheter fragment, as well as to accumulate an increased amount of biofilm (2-log CFU/mL) when compared with the $a g r$-functional isolate (Figure 7, top). The stability of the agr expression in the agr-dysfunctional MRSA was examined by observing the hemolytic activity of individual colonies. No hemolytic halo was detected before and after passages in mice (Figure 7, bottom).

\section{Expression of agr-regulated genes}

Total RNA obtained from isolates with significant differences $(p<0.001)$ in the RNAIII transcription level $(08-008$; $\mathrm{RQ}=0.0001 \pm 0.16$ and $96 / 05 ; \mathrm{RQ}=0.53 \pm 0.13$ ) was used to 


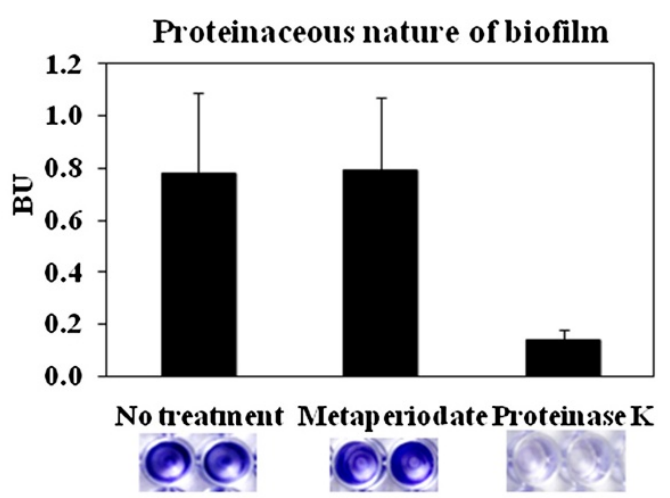

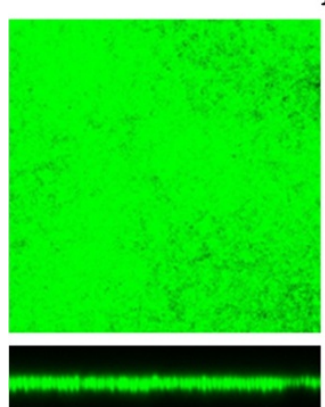

08-008 (untreated)

In vitro biofilm formation

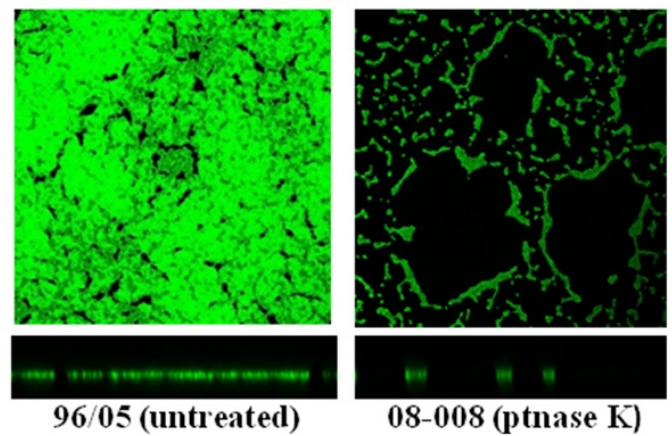

Figure 2 Proteinaceous nature of the biofilm. Top: Effect of $1 \mathrm{mM} /$ well sodium metaperiodate or $6 \mathrm{U} /$ well proteinase $\mathrm{K}$ on preformed biofilm. Wells show the effect of these compounds on biofilms preformed on inert polystyrene surfaces by representative ST1 isolates. Bottom: Confocal laser scanning microscopy (CLSM) images of proteinase K-treated and -untreated biofilms stained with SYTO 9. The square indicates the slice of the biofilm from which the XY image was taken. The horizontal bar indicates the location of the X plane from which the cross-section was taken. Isolate 08-008 (strong biofilm producer, agr-dysfunctional), 96/05 (moderate biofilm producer, agr-functional).

analyze the expression of genes that are well known to be regulated by agr. As expected, the agr-up-regulated hla was less expressed $(p<0.01)$ in the isolate 08-008 (Figure 8) when compared with the isolate $96 / 05(\mathrm{RQ}=0.05 \pm 0.01$ and $\mathrm{RQ}=0.33 \pm 0.05$, respectively). Similar pattern of expression was found for another agr-up-regulated gene, psm $\alpha$ $\left(\mathrm{RQ}_{96 / 05}=75.90 \pm 0.10\right.$ and $\left.\mathrm{RQ}_{08-008}=0.005 \pm 0.12 ; p<0.001\right)$, except that in this case we also observed a very high expression of psm $\alpha$ for 96/05 (Figure 8). To verify if this amplified expression was a characteristic of this MRSA clone, other $a g r$-functional isolates were randomly selected for testing. High level of psma transcripts was also detected for the isolates 07-035, 07-059 and 08-068 $\left(\mathrm{RQ}_{07} \quad 035=35.71 \pm 0.06 ; \mathrm{RQ}_{07-059}=48.90 \pm 0.07\right.$; $\left.\mathrm{RQ}_{08-068}=31.30 \pm 0.07\right)$. For all virulence genes tested, the expression of the agr-functional isolate BMB9393 was higher than that of USA400-related isolates, except for psma gene (Figure 8). Accordingly, the RNAIIIdown-regulated spa gene showed a very significant lower expression $(p<0.001)$ in the agr-functional 96/05 $(\mathrm{RQ}=0.8 \pm 0.20)$ compared with the agr-dysfunctional isolate 08-008 $(\mathrm{RQ}=52.8 \pm 0.17$; Figure 8).
Expression of biofilm-associated genes fnbAB, sasG and spa The agr-dysfunctional isolate 08-008, which showed increased biofilm accumulation in vitro and in vivo, had a significant increase $(p=0.02)$ in $f n b A$ transcripts $\left(\mathrm{RQ}_{f n b A}=10.08 \pm 0.18\right)$ when compared with the isolate 96/05 $\mathrm{RQ}_{f n b A}=4.91 \pm 0.19$; Figure 8). However, no significant difference was detected when $f n b B$ expression were analyzed $\left(\mathrm{RQ}_{96 / 05}=0.11 \pm 0.04 ; \mathrm{RQ}_{08-008}=0.18 \pm 0.05\right.$; Figure 8$)$. Similarly to $f n b A$, the expression of $\operatorname{sas} G$ (Figure $8 ; p=0.03$ ) and spa (Figure $8 ; p<0.001$ ) was also increased in $08-008$ $\left(\mathrm{RQ}_{\text {sas }}=1.13 \pm 0.11 ; \mathrm{RQ}_{\text {spa }}=52.8 \pm 0.17\right)$ compared with $96 / 05$ isolate $\left(\mathrm{RQ}_{s a s G}=0.65 \pm 0.14 ; \mathrm{RQ}_{s p a}=0.8 \pm 0.20\right)$.

\section{Adherence and invasion}

The naturally agr-dysfunctional isolate 08-008 showed significant increase $(p<0.05)$ in the adherence to human airway cells, reaching $25.27 \% \pm 0.4 \%$ at $3 \mathrm{~h} 30 \mathrm{~min}$ of incubation. In contrast, at the same conditions, the adherence of the $a g r$-functional (isolate 96/05) to airway cells occurred in much less extent $(4.94 \% \pm 0.2 \%)$. Similarly, invasion was also higher for the agr-dysfunctional isolate $(6.37 \% \pm 0.3 \%)$ when compared with the agr-functional $(1.76 \% \pm 0.2 \%)$ at 

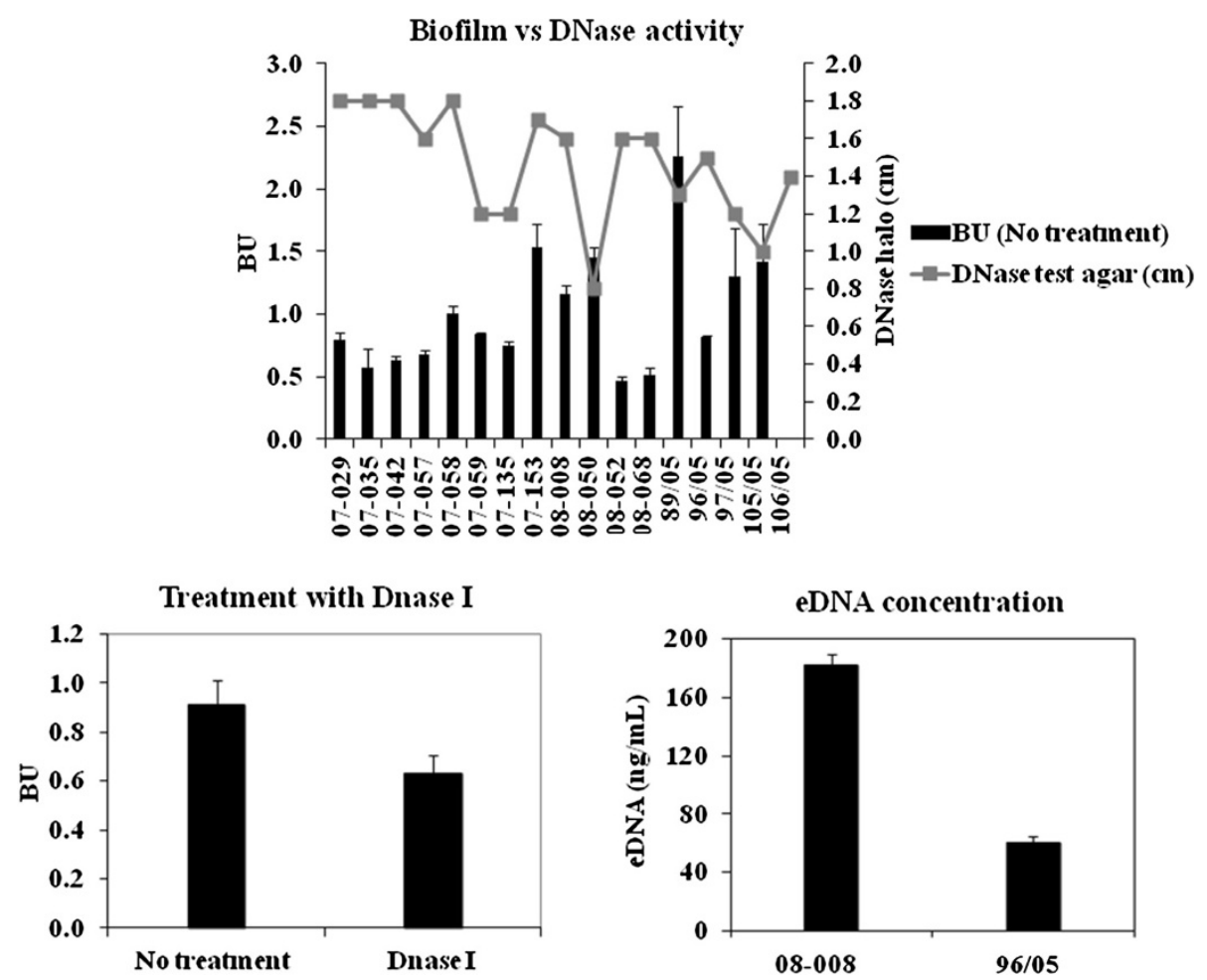

Figure 3 Bacterial DNase activity, treatment of the biofilm with DNase I and eDNA assay. Top: DNase activity was detected in culture supernatants of 16 ST1 isolates by measuring the halo size $(\mathrm{cm})$ produced on Difco ${ }^{\mathrm{TM}}$ DNase Test Agar (BD). BU: Biofilm values for 16 ST1 isolates using inert polystyrene. Left bottom: For 16 ST1 isolates, 56U/well of DNase I were added to the culture media and the amount of biofilm accumulated determined. Right bottom: The concentration of eDNA determined in the biofilm supernatant. Isolate 08-008 (strong biofilm producer, agr-dysfunctional), 96/05 (moderate biofilm producer, agr-functional).

3h30min incubation (Figure 9, top). Likewise, an increased invasive ability in the stationary phase was observed for the agr-knockout MHC474 (10.6\% $\pm 0.3 \%)$ when compared with the wild type (HC474; $2.8 \% \pm 0.1 \%)$ and complemented construction CMHC474 $(2.3 \% \pm 0.1 \%$; $p=0.0033$; Figure 9, bottom).

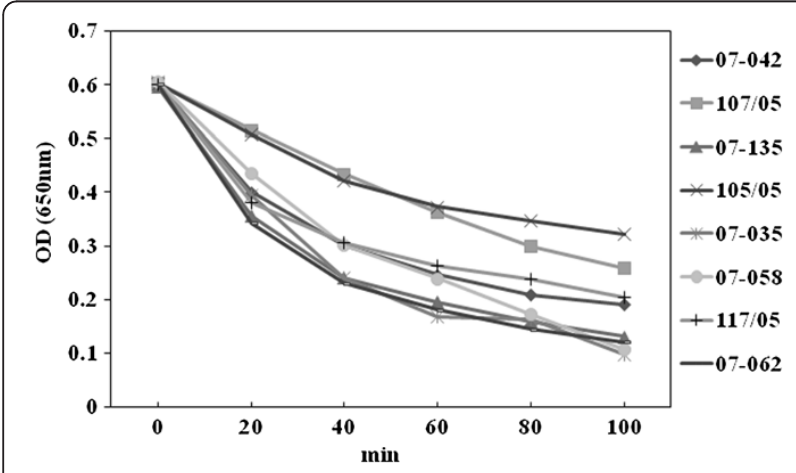

Figure 4 Autolysis assays for USA400-related isolates. 07-058, 105/05, 107/05 are strong biofilm producers; 07-035, 07-042, 07-135 moderate; and 07-062, 117/05 weak producers.

\section{Discussion}

The great majority of the USA400-related isolates $(50 / 60 ; 83.3 \%)$ were able to accumulate strong/moderate biofilms on polystyrene surfaces. The isolates remaining produced weak biofilms. The ability to accumulate biofilm increased when the surfaces were covered with human fibronectin, as also reported by others [19,29]. In opposition to our results, it was reported that MW2 MRSA had a weak biofilm phenotype [30,31]. Similarly, a slight biofilm accumulation $(\mathrm{OD}=0.25-0.3)$ was observed for another USA400 strain called BAA-1683 [32]. In addition, recent data from our laboratory (Ramundo MS \& Figueiredo AMS, 2012; unpublished observations) showed that another SCCmecIV isolates (ST30 CA-MRSA) accumulated much lower amount of biofilm compared with ST1-SCC mecIV isolates.

Previous data from our group [12] have also demonstrated that the ST1 isolates from Rio de Janeiro do not carry lukSF genes and have acquired a number of antimicrobial resistance traits. Thus, it is possible that the enhanced ability to accumulate biofilm, associated with the biological cost of acquired resistance and the absence of PVL, might have been the results (at least in part) of the 

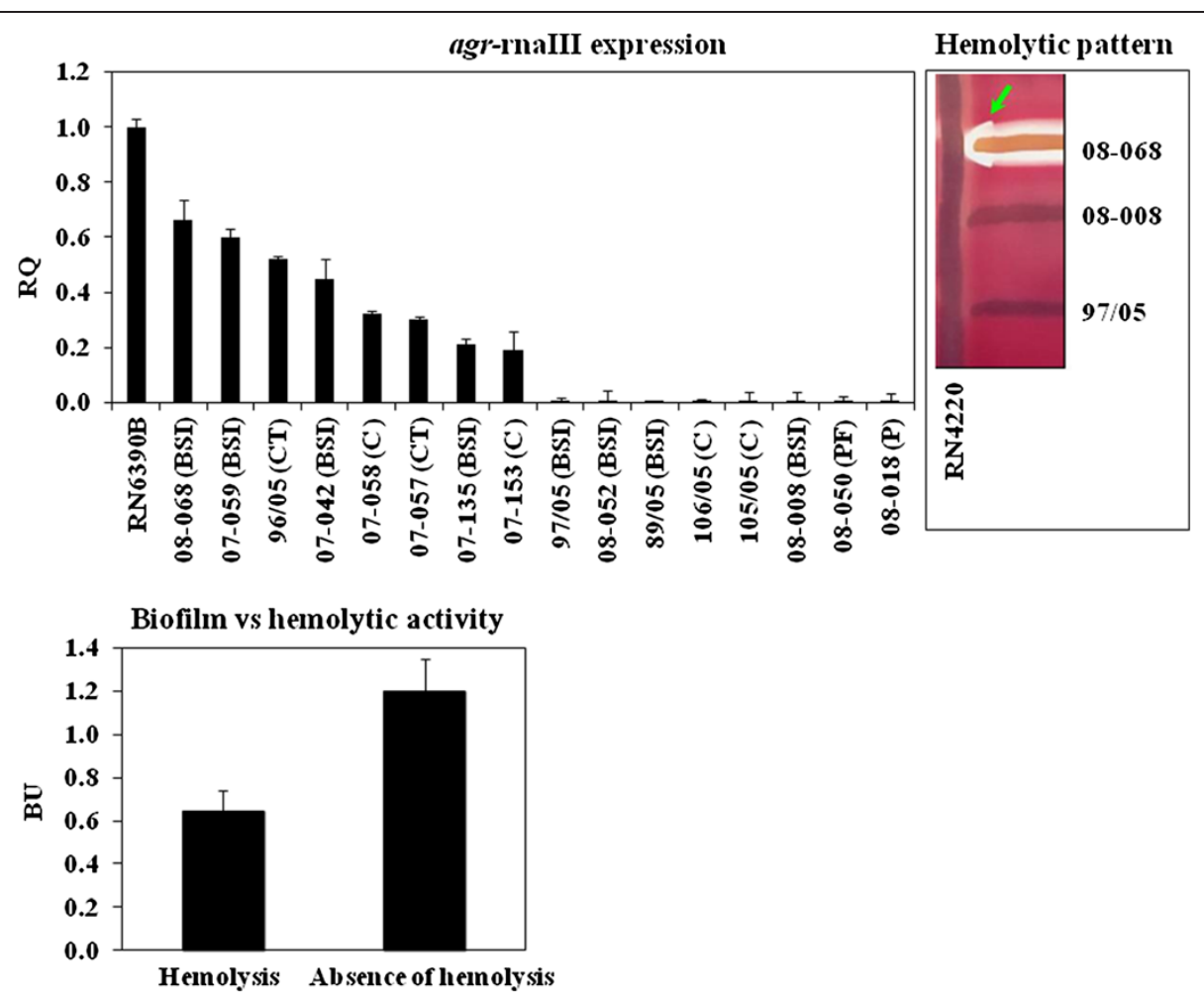

Figure 5 agr differential expression in USA400-related isolates. Top left: rnall expression was analyzed by RT-qPCR using $\triangle \triangle C_{T}$ comparative method. RQ: Relative quantity, (BSI): bloodstream infection, (CT): catheter tip, (P): Pneumonia, (C): colonization and (PF): prosthesis fragment. Top right: The arrow indicates the arrow-tip-like zone of the $\delta$-hemolysin activity on sheep blood agar. Bottom: Mean biofilm values (BU) for the populations formed by isolates showing hemolytic activity or absence of hemolysis.

microevolutionary events that accounted for changes in a previously community pathogen, promoting enhanced bacterial fitness to spread in hospitals and cause health-care associated diseases. The ica-independent nature of the biofilm formed by USA 400-related isolates was revealed by the disruption of bacterial film by proteinase K. Similar

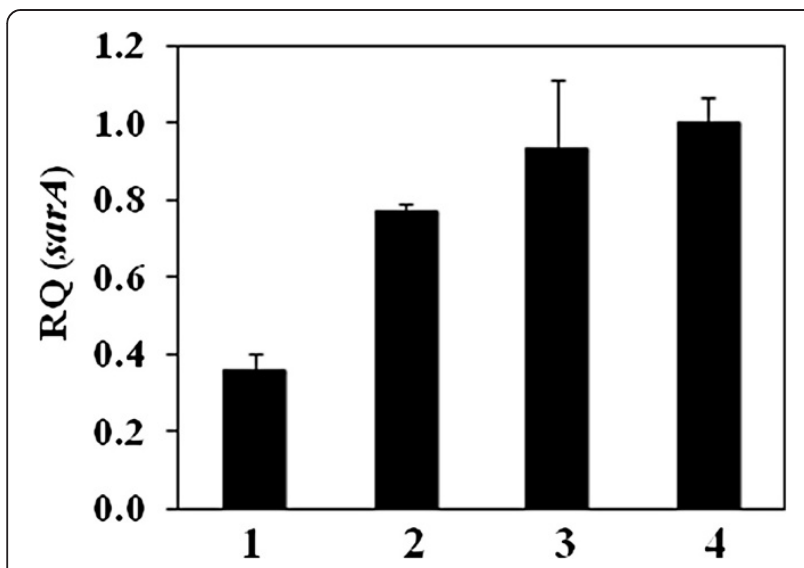

Figure 6 Transcriptional levels of sarA determined by using $\Delta \mathbf{\Delta} \mathbf{C}_{\mathrm{T}}$ comparative method. (1) USA400-related isolates 08-008 (agr-dysfunctional) and (2) 96/05 (agr-functional). (3) BMB9393 was used as a control and (4) RN6390B as calibrator. RQ: Relative quantity. results were also observed by others using different MRSA isolates $[33,34]$. Some researchers have suggested that the bacterial autolysis increases eDNA concentration and, consequently, enhances the level of biofilm accumulation [20]. In fact, in our study, we observed a moderate correlation between biofilm accumulation and autolysis. In addition, we detected threefold increase in eDNA for the ST1 MRSA displaying enhanced ability to accumulate biofilm. Indeed, the addition of DNase I (56U/Well) caused a significant reduction (about 30\%) in biofilm accumulation, suggesting eDNA cooperatively contributes to the biofilm architecture of ST1 isolates.

The statistical analysis showed that the group of clinical isolates with no hemolytic activity (agr-dysfunctional) had significant increase in the level of biofilm accumulation when compared with $a g r$-functional isolates. These data are in agreement with previous studies for agr-laboratory knockouts $[27,35,36]$, which have indicated that some agr mutants can display increased levels of biofilm accumulation. In spite of that, using another S. aureus strain it was reported that inhibition of agr reduced biofilm accumulation significantly [24,25]. In fact, agrRNAIII is a negative regulator of different surface proteins $[22,23]$, and consistent with this regulation, amplified expression of genes encoding for biofilm-associated proteins FnBPA, 


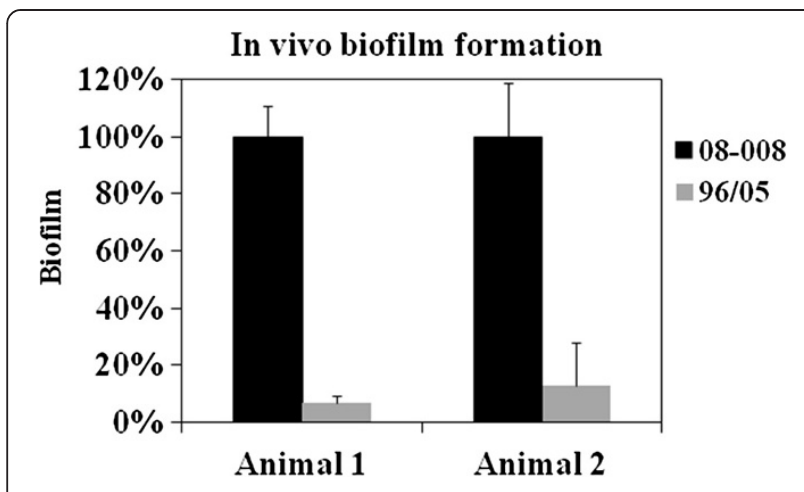

Stability of agr inactivation

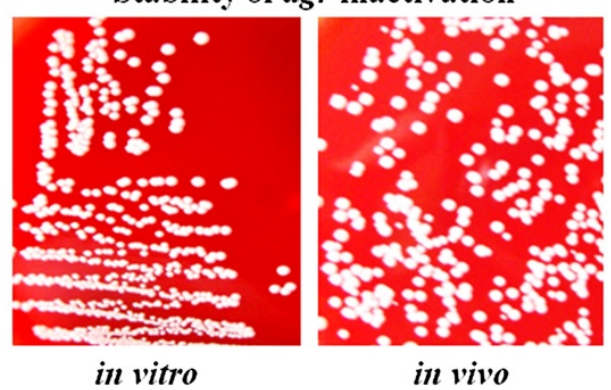

Figure 7 In vivo biofilm accumulation and stability of $a g r$ inhibition. Top: For the foreign body animal model, data were transformed in percentage considering the CFU/mL of the isolate 08-008 as the reference value (100\%). Bottom: The stability of agr inhibition was tested by examining the hemolytic activity of individual colonies of the isolates 08-008 before (left) and after (right) passage in the animal.

SasG and Spa was found for the agr-dysfunctional variant. Both FnBPA and B have been implicated as major proteins for biofilm formation/accumulation in S. aureus [19,33]. However, despite the detection of an enhanced expression of $f n b A$, we could not find a significant increase in the transcription of $f n b B-m R N A$ for the agr-dysfunctional ST1-MRSA. Equally, a study from Wolz and collaborators suggested that $f n b B$ was not significantly affected by agr [36].

Confirming the agr inhibition detected, the expression of two genes up-regulated by RNAIII, hla and $p s m \alpha$, was lower compared with the agr-functional MRSA. Both cytolysins (HLA and PSM $\alpha$ ) seem to have remarkable roles in the pathogenesis of $S$. aureus. HLA has been associated with lethal pneumonia in USA400 and USA300 strains $[37,38]$. It was also previously found that psmadeleted mutant of CA-MRSA exhibited attenuated virulence in animal models [39]. In this study, we detected a superior expression of $p m s \alpha$ by the $a g r$-functional isolates of USA400-related clone detected in Rio de Janeiro. In fact, it was shown by others that the transcription of psm $\alpha$-mRNA was increased in most prevalent CA-MRSA lineages, including MW2, compared with other S. aureus isolates [39]. However, the molecular mechanisms involved with the enhanced expression of PSM $\alpha$ were not clarified [39]. Despite the importance of these virulence factors for S. aureus pathogenicity, it is remarkable that among the agr-dysfunctional variants, 4 were recovered from cases of BSI, 2 from colonization, 1 from pneumonia and 1 from infected prosthesis, showing that these variants were able to colonize and cause both severe acute (pneumonia and BSI) and chronic (foreign-body infection) staphylococcal diseases in humans. These data demonstrated that regardless the reduced virulence of agr-laboratory knockouts in some animal models [40], the virulence of naturally dysfunctional $a g r$ variants was confirmed for hospitalized patients. In contrast to the assumption that agr-dysfunctional isolates may not be able to initiate infections [41], the isolate 08-008 was able to colonize polyurethane endovenous catheter in a foreign-body mouse model, forming a denser biofilm accumulation when compared with the $a g r$-functional isolate. It is important to state that because the ST1 isolates studied were not isogenic, it is possible that factors other than the inhibition of agr might also have accounted for the increased biofilm accumulation observed. Nevertheless, supporting our data, similar increase of the biofilm formed on catheters implanted in mice was previously reported for an agr laboratory knockout [28]. In opposition to the results obtained by Traber et al. [41], all individual colonies formed by the agr-dysfunctional MRSA remained non-hemolytic before and after passages in mice, strongly suggesting the genetic stability of the phenotype. This stability was confirmed for all $a g r$-dysfunctional isolates from our collection. Corroborating our findings, while we were finishing this manuscript, we noticed the work by Park et al. [42] that found agr dysfunction in S. aureus significantly associated with persistent bacteremia with eradicated foci, even though the predominant MRSA isolates showed SCCmecII, agrII (possible belonging to USA100New York/Japan clone) while the isolates studied here displayed SCCmecIV, agrIII and clustered in USA400MW2/WA-1 clone. In fact, the bacterial ability to adhere to and invade epithelial cells, and consequently evade host defense mechanisms, has already been associated with persistence in host cells and development of disseminated infections $[43,44]$. In the present study, the differential expression of agrRNAIII in MRSA clinical isolates had a significant impact on adherence and invasion at $3 \mathrm{~h} 30 \mathrm{~min}$ incubation. The same impact was observed for the agr isogenic knockout, as previously showed by others using different cell lines and mostly laboratory mutants $[26,45]$.

Recently, Pozzi et al. demonstrated that high level of PBP2a expression by the homogeneous methicillin-resistant derivative of the strain 8325-4 induced a proteinaceous biofilm and significant repression of the agr locus [46]. In addition, excision of the SCCmec element from the MRSA 

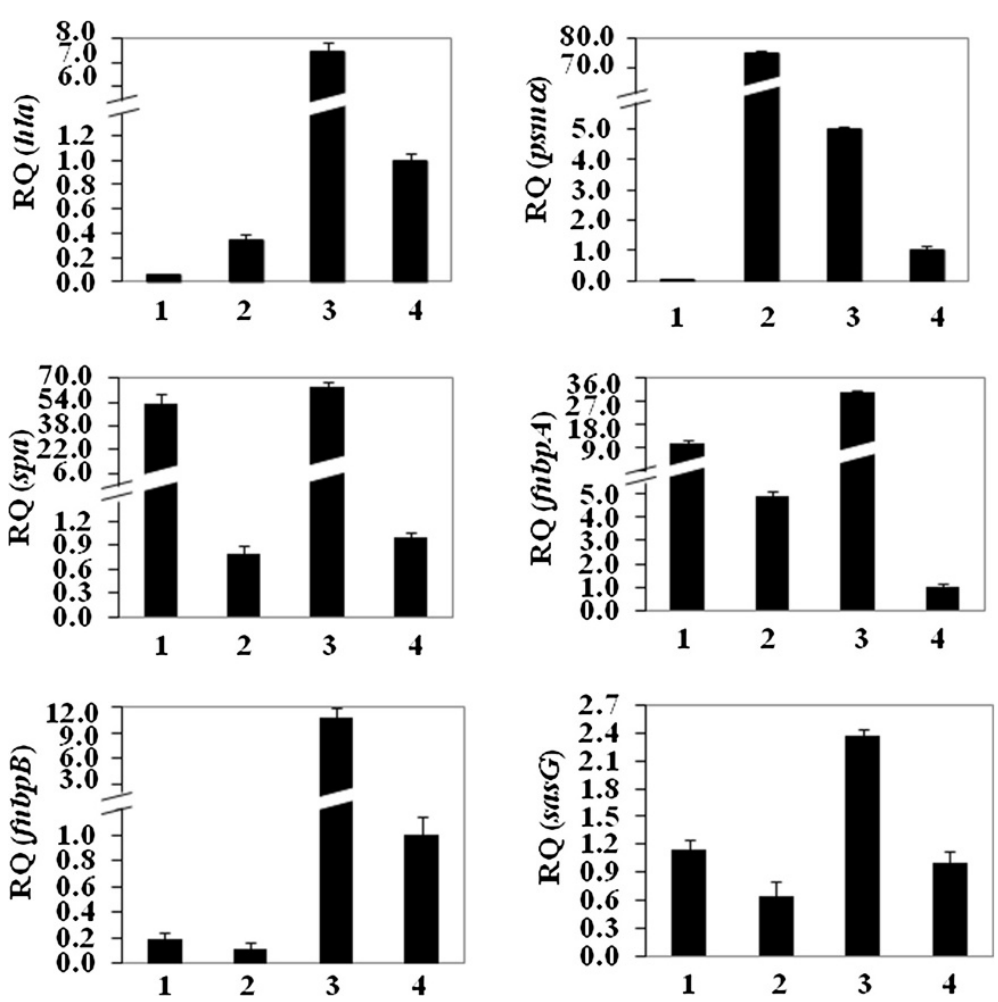

Figure 8 Transcriptional levels of virulence-associated genes determined by RT-qPCR, using $\Delta \Delta C_{T}$ comparative method. (1) USA400-related isolates 08-008 (agr-dysfunctional) and (2) 96/05 (agr-functional). (3) BMB9393 was used as a control and (4) RN6390B as calibrator. RQ: Relative quantity.

strain BH1CC, with consequent loss of oxacillin resistance, had the opposite effect on biofilm and lead to an increase of the agrRNAIII transcription. In addition, Rudkin et al. showed that methicillin resistance reduced the virulence of HA-MRSA by interfering with agr [47]. The great majority of ST1 isolates studied had MIC of $128 \mu \mathrm{g} / \mathrm{mL}$ (agr-functional or -dysfunctional), which is compatible with heterogeneous resistance to this drug. Indeed, mecA overexpression was not detected in the agr-dysfunctional isolates tested. SarA, a global transcriptional regulator of S. aureus, was previously found to be a positive regulator of $a g r$ and of biofilm formation/accumulation [21,48]. Thus, aiming to understand the mechanism involved in agr impairment in these clinical isolates, the level of $\operatorname{sar} A$ transcripts was also examined. It was observed that sarA expression was significantly diminished in the agr-dysfunctional compared with the agr-functional MRSA, suggesting the defect was upstream agr. Beeken et al. indicated that sarA repression inhibited biofilm accumulation due to SarA inhibition of both proteases and nucleases activity either in the presence or absence of $a g r$ mutations [49]. In contrast, the results obtained here demonstrated that agr-dysfunctional isolates showed increased biofilm accumulation, despite the fact that sarA-mRNA transcripts were reduced. In fact, other studies have showed that sarA or agr-sarA laboratory mutants had lower ability to bind to fibronectin due to sarA down-regulation of $f n b A$ transcription [36]. Possible explanations for this apparent divergence could be the fact that the agr-dysfunctional ST1 studied showed only partial sarA inhibition, or may display strain-dependent variation in the genetic background affecting other genes apart to those studied.

\section{Conclusion}

Isolates of this novel hospital-associated USA400 clone were able to accumulate moderate/strong amount of biofilms, in vitro and in vivo, and could efficiently adhere to and invade human airway cells. Moreover, agr inhibition was an ordinary phenomenon among those isolates, which seems to have impacted the expression of some important virulence genes studied. Although it is difficult to interpret in vitro studies in the light of what occurs in an infected human host, it follows logical that the enhanced adhesive properties combined with the acquisition of multiple drug resistance traits by ST1 isolates could have provided fitness advantages for spreading in hospital environments. Indeed, $a g r$-dysfunctional isolates were recovered from cases of hospital pneumonia, bacteremia and infected prosthesis. Finally, our results strongly suggest that strategies for controlling MRSA biofilm based on agr inhibition approaches are unlikely to be effective, at least for ST1 MRSA isolates. 


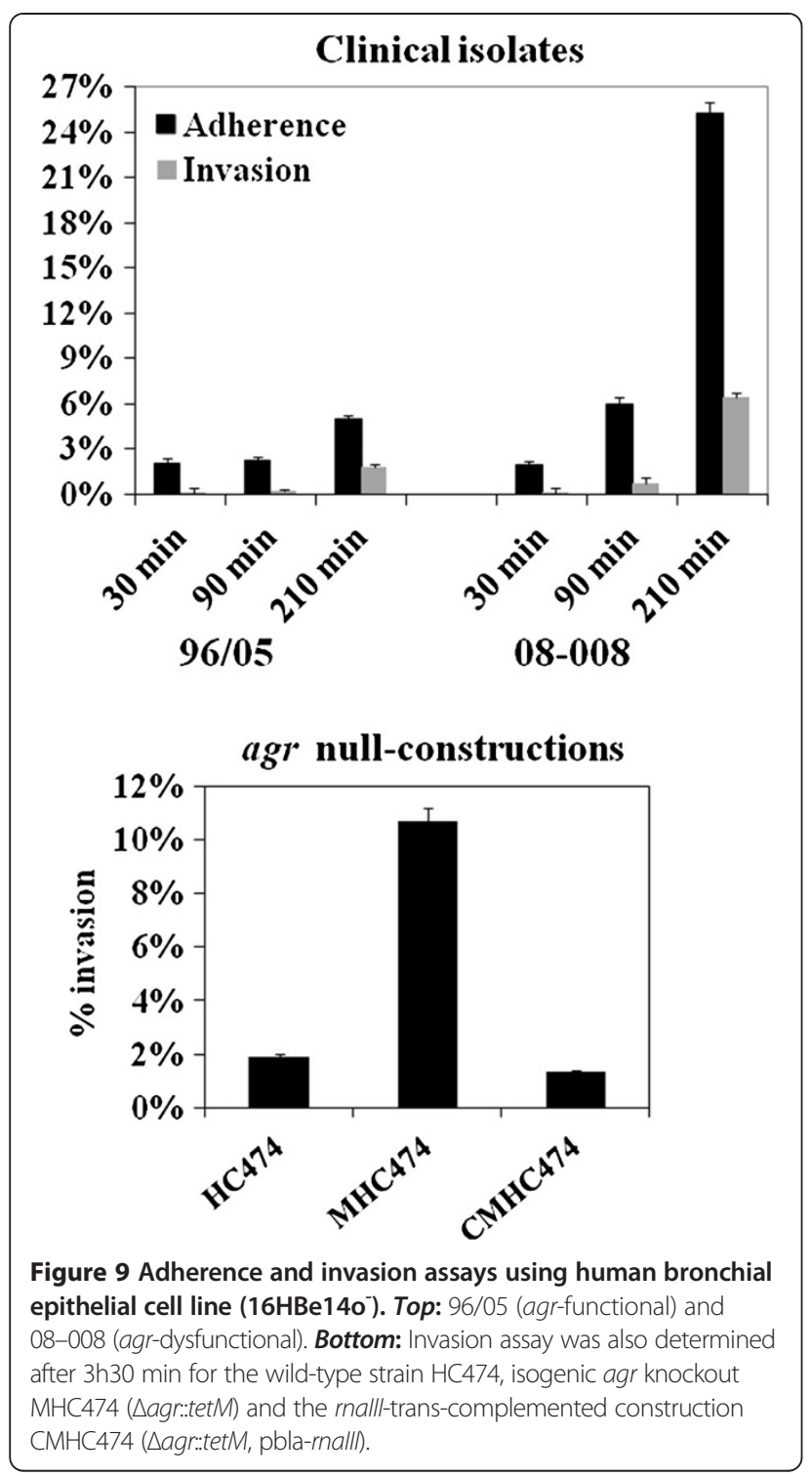

\section{Methods}

\section{Isolates}

Sixty USA400-related isolates were obtained from patients located in different hospital wards in Rio de Janeiro as part of standard clinical care. Thirty isolates were recovered from BSI (50\%) and 8 from catheter tips (CT; 13.3\%). The remaining were from colonization $(\mathrm{C} ; 13.3 \%)$, pneumonia (P; 6.7\%), skin/soft tissue infections (SSTI; 5\%), urinary tract infections (UTI; 3.3\%) and prosthesis fragment (PF; 1.7\%). The infection sites had not been reported for 4 isolates. The agr-knockout MNY474 (Aagr::tetM) and the rnaIII-trans-complemented mutant CMNY474 ( $\Delta$ agr::tetM, pbla-rnaIII) were previously constructed from the clinical S. aureus isolate NY474 [27]. BMB9393 (ST239-SCCmecIII) was used as positive control for biofilm and gene expression experiments [27]. The
S. aureus RN4220 and RN6390B, a gift from Richard Novick (New York University), were used for hemolytic activity and gene expression analyses; respectively. This study was approved (\#1055/09) by the Human Research Ethics Committee from Federal University of Rio de Janeiro, RJ, Brazil.

Minimal inhibitory concentration (MIC)

Oxacillin MIC was determined using Müller Hinton plates and performed in accordance with the Clinical Laboratories Standards Institutes (CLSI) guidelines [50].

\section{In vitro biofilm assay}

For all 60 isolates, biofilm was tested using 96-well inert polystyrene microtiter plates (Nunclon; Nunc A/S, Roskilde, Denmark) as previously described [28]. The biofilm unit (BU) was defined as indicated by Amaral et al. [14] and the isolates were classified as non-producers (BU $\leq 0.230)$, weak (BU>0.230 and $\leq 0.460)$, moderate ( $\mathrm{BU}>0.460$ and $\leq 0.920$ ) or strong producers (BU>0.920), as suggested [14]. For 19 isolates, biofilm assays were also carried out on surfaces covered with human fibronectin (Merck; Darmstadt, Germany) as previously described [28].

In some experiments, before treatment with crystal violet, the biofilm was treated with sodium metaperiodate (10mM/well; Sigma; St. Louis, MO, USA) or proteinase K (6U/well, Invitrogen; Carlsbad, California, EUA) [27]. Confocal laser scanning microscopy (CLSM) was employed to record and contrast structural images of the biofilm as described [28]. eDNA was quantified in biofilm supernatants using Qubit ${ }^{\circledR} 2.0$ Fluorometer (Invitrogen; Eugene, Oregon, USA), after ethanol precipitation. For some experiments, biofilms were formed in the presence of DNase I (28U/well or 56U/well Invitrogen; Carlsbad, California, EUA).

\section{Animal model}

A pair of isolates showing differential agr expression (08-008, agr-dysfunctional, obtained from BSI and 96/05, agr-functional, from CT) was used. The mouse subcutaneous catheter implant model was described in detail by Ferreira et al. [28]. Briefly, two intravenous polyurethane catheter segments (C-UDLM-953J model; Cook Medical, Bloominaton, USA) were implanted in the back of each anesthetized young-adult BALB/c male mice. Infection was induced $24 \mathrm{~h}$ after the implantation procedure by injecting a mid-exponential growth phase culture $\left(10^{6} \mathrm{CFU} / 10 \mu \mathrm{L}\right)$ into the lumen of the implanted catheter segment. The animal was euthanized after three days post-infection, and the catheter segments were surgically removed to assess the biofilm by counting catheter-adherent bacteria by CFU determination. Three independent experiments were performed. The animal study was approved (\#IMPPG013) 
by The Ethics Committee for Animal Care and Use from Federal University of Rio de Janeiro, RJ, Brazil.

\section{DNase activity}

Difco $^{\mathrm{TM}}$ DNase Test Agar (BD; Becton, Dickinson and Company, Sparks, USA) was used to screen 17 USA400related MRSA, as recommended by the manufacturer.

\section{Autolysis assay}

Autolysin activity was measured in 8 selected isolates as previously described [51], except that cells were grown in TSB $1 \%$ Glc.

\section{Hemolytic activity}

The $\delta$-hemolysin (HId), encoded by the hld gene, is codified within the rnaIII region and, consequently, the detection of $\delta$-hemolysin is an indicative of $a g r$ expression. Sixty USA400-related isolates were screened for hemolytic activity on sheep red blood (5\%) agar plates (Plast Labor, RJ, Brazil) as previously described [52].

\section{Gene expression}

For RNA preparations, bacterial cells grown in TSB $\left(18 \mathrm{~h} / 37^{\circ} \mathrm{C} ; 250 \mathrm{rpm}\right)$ were obtained in the exponential phase $\left(\mathrm{OD}_{600 \mathrm{~nm}}=0.3\right)$ and in the stationary phase. Total RNA was prepared using the RNeasy Mini kit (Qiagen; Maryland, USA) and quantified by the Qubit 2.0 Fluorometer. The RNA quality was analyzed by running RNA-gel electrophoresis. The real-time quantitative PCR (RT-qPCR) was carried out using Power SYBR $^{\circledR}$ Green RNA-to- $\mathrm{C}_{\mathrm{T}}{ }^{\mathrm{T}}{ }^{\mathrm{M}} 1$-Step Kit (Applied Biosystems; Foster city, CA, USA) as recommended, using $\Delta \Delta \mathrm{Ct}$ comparative method. The primers and run conditions used for rnaIII, hla, psma [53], sarA, mecA[54], spa, sasG, fnbA and $f n b B$ genes and for the endogenous control rrna $16 \mathrm{~S}$ are listed in Table 1. All primers designed for this study were validated as recommended (Guide to Performing Relative Quantitation of Gene Expression Using Real-Time Quantitative PCR; Applied Biosystems). The run was performed in the Step One ${ }^{\mathrm{TM}}$ Real Time PCR System (Applied Biosystems). Data were analyzed using the Step One Software 2.2 (Applied Biosystems).

\section{Adherence and invasion kinetics}

Bacterial adherence and invasion were investigated using human bronchial epithelial cells (16HBE14o- cell line) as described [14], except that monolayers were prepared using Dulbecco's Modified Eagle Medium (DMEM, Low Glucose 1X; Gibco, Invitrogen, Grand Island, USA) and $10 \%$ Fetal Bovine Serum (Gibco, Invitrogen). For determining the colony forming units (CFU) of the total adhered and invasive bacteria $\left(\mathrm{CFU}_{\mathrm{AI}}\right)$, infected monolayers were washed twice in DMEM (to remove non-adherent bacteria), incubated $\left(5 \mathrm{~min} / 37^{\circ} \mathrm{C}\right)$ with
Table 1 Primers used in Real Time qPCR

\begin{tabular}{|c|c|c|c|}
\hline $\begin{array}{l}\text { Target } \\
\text { gene }\end{array}$ & Primer sequence $^{a}$ & $\begin{array}{l}\text { Amplicon } \\
\text { length (bp) }\end{array}$ & Reference \\
\hline \multirow[t]{2}{*}{ rnalll } & F: AATTTGTTCACTGTGTCGATAAT & 135 & This study \\
\hline & R:TGGAAAATAGTTGATGAGTTGTT & & \\
\hline \multirow[t]{2}{*}{ sarA } & F: TTCTITCTCTITGTITCGCTG & 115 & This study \\
\hline & R: GTTATCAATGGTCACTTATGCT & & \\
\hline \multirow[t]{2}{*}{ spa } & F: TGGTTTGCTGGTTGCTTCTTA & 116 & This study \\
\hline & R: GCAAAAGCAAACGGCACTAC & & \\
\hline \multirow[t]{2}{*}{ hla } & F: TTTGTCATTTCTTCTTITTCCCA & 169 & This study \\
\hline & R: AAGCATCCAAACAACAAACAAAT & & \\
\hline \multirow[t]{2}{*}{ psma } & F:TATCAAAAGCTTAATCGAACAATTC & 176 & 53 \\
\hline & R: CCCCTTCAAATAAGATGTTCATATC & & \\
\hline \multirow[t]{2}{*}{ sas $G$} & F:GGTTTCAGGTCCTTTGGAT & 192 & This study \\
\hline & R:CTGGTGAAGAGCGAGTGAAA & & \\
\hline \multirow[t]{2}{*}{ fnbpA } & F: ACTTGATTITGTGTAGCCTTITT & 185 & This study \\
\hline & R:GAAGAAGCACCAAAAGCAGTA & & \\
\hline \multirow[t]{2}{*}{ fnbp $B$} & F:CGTTATTGTAGTTGTTTGTGTT & 118 & This study \\
\hline & R:TGGAATGGGACAAGAAAAAGAA & & \\
\hline \multirow[t]{2}{*}{ rrna $16 \mathrm{~S}$} & F: AGAGATAGAGCCTTCCCCTT & 84 & This study \\
\hline & R:TTAACCCAACATCTCACGACA & & \\
\hline \multirow[t]{2}{*}{ mecA } & F:TCCAGATTACAACTTCACCAGG & 162 & 54 \\
\hline & R:CCACTTCATATCTTGTAACG & & \\
\hline
\end{tabular}

${ }^{\mathrm{a}} \mathrm{F}$ and $\mathrm{R}$ : forward and reverse primers, respectively, in $5^{\prime} \rightarrow 3^{\prime}$ orientation. The cycling conditions for all primers were as follows: One cycle of $48^{\circ} \mathrm{C} / 30 \mathrm{~min}$ and $95^{\circ} \mathrm{C} / 10 \mathrm{~min}$, followed by 35 cycles of $95^{\circ} \mathrm{C} / 30 \mathrm{~s}, 55^{\circ} \mathrm{C} / 45 \mathrm{~s}$ and $72^{\circ} \mathrm{C} / 45 \mathrm{~s}$. Each run included a nontemplate and a gene-negative RNA controls.

0.25\% (wt/vol) trypsin (11,000 U/mg; Sigma; St. Louis, MO USA), lysed $\left(5 \mathrm{~min} / 37^{\circ} \mathrm{C}\right)$ with $0.025 \%$ ( $\mathrm{vol} / \mathrm{vol}$ ) Triton X-100 (Sigma) and plated in TSA. For determining the CFU of invasive bacteria $\left(\mathrm{CFU}_{\mathrm{I}}\right)$, infected monolayers were washed twice in DMEM and incubated $\left(20 \mathrm{~min} / 37^{\circ} \mathrm{C}\right)$ with $100 \mu \mathrm{g} / \mathrm{mL}$ lysostaphin (500 U/mg; Sigma) to lyse adherent bacteria. Monolayers were washed twice and incubated $\left(5 \mathrm{~min} / 37^{\circ} \mathrm{C}\right)$ with $0.25 \%(\mathrm{wt} / \mathrm{vol})$ trypsin. The epithelial cells were lysed $\left(5 \mathrm{~min} / 37^{\circ} \mathrm{C}\right)$ with $0.025 \%$ (vol/vol) triton X-100 and plated. For each aliquot, the total CFU in the supernatant was also determined $\left(\mathrm{CFU}_{\mathrm{S}}\right)$. The CFU of adherent bacteria $\left(\mathrm{CFU}_{\mathrm{A}}\right)$ was obtained by the formula: $\mathrm{CFU}_{\mathrm{A}}=\mathrm{CFU}_{\mathrm{AI}}-\mathrm{CFU}_{\mathrm{I}}$. The percentages of invasive or adherent bacteria were calculated considering as $100 \%$ the total CFU obtained by the sum of $\mathrm{CFU}_{\mathrm{AI}}+\mathrm{CFU}_{\mathrm{S}}$ for each aliquot. In addition to the USA400-related isolates, the wild-type HC474, and the isogenic $\triangle$ agr::tetM and rnaIII-trans-complemented constructions were also used for investigating bacterial invasion.

\section{Statistical calculations}

Student's $t$-test (unpaired data) was used to compare the means of the biofilm values and of the data from gene expression experiments. In addition, correlation coefficient 
(r) was used to test the relationship between the autolysis and the ability of ST1 isolates to accumulate strong or weaker biofilms. This last test was also used to determine the occurrence of linear correlation between mecA and agr expressions [55]. Data were expressed in terms of mean values obtained from at least three independent experiments and three repetitions of each set.

\begin{abstract}
Abbreviations
Agr: Accessory gene regulator; BSI: Bloodstream infection; BU: Biofilm unit; C: Colonization; CA-MRSA: Community-acquired Methicillin-resistant Staphylococcus aureus; CFU: Colony-forming unit; CLSM: Confocal laser scanning microscopy; CT: Catheter tip; DNase: Desoxyribonuclease; DMEM: Dulbecco's Modified Eagle Medium; eDNA: Extracellular DNA; Fn: Fibronectin; fn $b A B$ : Genes encoding for fibronectin-binding protein $A$ and $B$; FnBPA/FnBPB: Fibronectin-binding protein A and B; ica: Operon encoding for enzymes involved in the synthesis of the polysaccharide of intercellular adhesion (PIA); HA-MRSA: Hospital-associated methicillin-resistant Staphylococcus aureus; Hla: a-Hemolysin; HId: $\delta$-Hemolysin; lukSF: Genes involved in the synthesis of the subunits $\mathrm{S}$ and $\mathrm{F}$ of the Panton Valentine leukocidin; MIC: Minimal inhibitory concentration; mecA: Gene encoding for penicillin-binding protein 2A; MRSA: Methicillin-resistant Staphylococcus aureus; OD: Optical density; P: Pneumonia; PBP2A: Penicillin-binding protein 2A; PCR: Polymerase chain reaction; PF: Prosthesis fragment; Psm: Phenol-soluble modulin; PVL: Panton-Valentine leukocidin; r: Correlation coefficient; Rot: Repressor of toxins; RQ: Relative quantity; RT-qPCR: Real time quantitative polymerase chain reaction; rrna 16S: Gene encoding for ribosomal RNA 16S; SarA: Transcriptional regulator SarA; SasG: S. aureus surface protein G; SCCmec: Staphylococcal cassette chromosome mec; ST: Sequence-type; Spa: Protein A; SSTI: Skin and soft tissue infections; TSB: Tryptic soy broth; TSB 1\% Glu: Tryptic soy broth supplemented with 1\% glucose; UTI: Urinary tract infections.
\end{abstract}

\section{Competing interests}

The authors declare that they have no competing interests.

\section{Authors' contributions}

FAF wrote the draft paper and carried out the experiments of biofilm formation/accumulation on inert polystyrene surfaces, DNase activity, autolysis assay, hemolytic activity, gene expression experiments, DNA Sequencing and statistical calculations. RRS, MAA and SELF carried out experiments of the animal model including animal surgery and observation, and biofilm determinations. RRS also carried out oxacillin MIC determinations. BSM carried out the experiments of biofilm formation/ accumulation on inert polystyrene surfaces and also on implanted catheters. AMAF and JNS carried out studies of adherence and invasion kinetics. AMSF carried out the experiments on mecA gene expression and was responsible for the study design, methodology used, wrote and review the draft paper and gave final approval of the manuscript. All authors read and approved the final manuscript. All authors contributed significantly for the conduction of the studies and discussion of the results.

\section{Acknowledgements}

This work was supported in part by Conselho Nacional de Desenvolvimento Científico e Tecnológico (CNPq), Fundação de Amparo à Pesquisa do Rio de Janeiro (FAPERJ), Coordenação de Aperfeiçoamento de Pessoal de Nível Superior (CAPES) and by European Commission's Seventh Framework Programme (FP7), through the Marie Curie International Research Staff Exchange Scheme NANO_GUARD (PIRSES-GA-2010-269138).

\section{Author details}

'Departamento de Microbiologia Médica, Instituto de Microbiologia Paulo de Góes, Universidade Federal do Rio de Janeiro, Rio de Janeiro, RJ, Brazil. ${ }^{2}$ Departmento de Virologia, Universidade Federal do Rio de Janeiro, Instituto de Microbiologia Paulo de Góes Rio de Janeiro, Rio de Janeiro, RJ, Brazil.

Received: 5 November 2012 Accepted: 22 April 2013

Published: 27 April 2013

\section{References}

1. Centers for Disease Control and Prevention: Community-acquired methicillin-resistant staphylococcus aureus infections-Michigan. MMWR Morb Mortal Wkly Rep 1981, 30:185-187.

2. Centers for Disease Control and Prevention: Four pediatric deaths from community-acquired methicillin-resistant staphylococcus aureus: Minnesota and north Dakota, 1997-1999. MMWR Morb Mortal Wkly Rep 1999, 48:707-710.

3. Herold BC, Immergluck LC, Maranan MC, Lauderdale DS, Gaskin RE, BoyleVavra S, Leitch CD, Daum RS: Community-acquired methicillin-resistant staphylococcus aureus in children with no identified predisposing risk. JAMA 1998, 279:593-598.

4. David MZ, Daum RS: Community-associated methicillin-resistant staphylococcus aureus: epidemiology and clinical consequences of an emerging epidemic. Clin Microbiol Rev 2010, 23:616-687.

5. Skov R, Christiansen K, Dancer SJ, Daum RS, Dryden M, Huang YC, Lowy FD: Update on the prevention and control of community-acquired methicillinresistant staphylococcus aureus (CA-MRSA). Int J Antimicrob Agents 2012, 39:193-200.

6. Diep BA, Chan L, Tattevin P, Kajikawa O, Martin TR, Basuino L, Mai TT, Marbach H, Braughton KR, Whitney AR, Gardner DJ, Fan X, Tseng CW, Liu GY, Badiou C, Etienne J, Lina G, Matthay MA, DeLeo FR, Chambers HF: Polymorphonuclear leukocytes mediate staphylococcus aureus Panton-valentine leukocidininduced lung inflammation and injury. Proc Natl Acad Sci USA 2010, 107:5587-5592.

7. Löffler B, Hussain M, Grundmeier M, Brück M, Holzinger D, Varga G, Roth J, Kahl BC, Proctor RA, Peters G: Staphylococcus aureus Panton-valentine leukocidin is a very potent cytotoxic factor for human neutrophils. PLOS Pathog 2010, 6:e1000715.

8. Otto M: A MRSA-terious enemy among us: end of the PVL controversy? Nat Med 2011, 17:169-170.

9. Hudson LO, Murphy CR, Spratt BG, Enright MC, Terpstra L, Gombosev A, Hannah P, Mikhail L, Alexander R, Moore DF, Huang SS: Differences in methicillin-resistant staphylococcus aureus (MRSA) strains isolated from pediatric and adult from hospitals in a large California county. J Clin Microbiol 2011, 50:573-579.

10. David MZ, Rudolph KM, Hennessy TW, Boyle-Vavra S, Daum RS: Molecular epidemiology of methicillin-resistant staphylococcus aureus rural southwestern Alaska. Emerg Infect Dis 2008, 14:1693-1699.

11. Golding GR, Levett PN, McDonald RR, Irvine J, Quinn B, Nsungu M, Woods S, Khan M, Ofner-Agostini M, Mulvey MR, Northern Antibiotic Resistance Partnership: High rates of staphylococcus aureus USA400 infection, northern Canada. Emerg Infect Dis 2011, 17:722-725.

12. Silva-Carvalho MC, Bonelli RR, Souza RR, Moreira S, dos Santos LC, de Souza Conceição M, de Mello Junior SJ, Carballido JM, Vieira W, Teixeira LA, Sá Figueiredo AM: Emergence of multiresistant variants of the communityacquired methicillin-resistant staphylococcus aureus lineage ST1-SCCmedV in 2 hospitals in Rio de Janeiro, brazil. Diagn Microbiol Infect Dis 2009, 65:300-305.

13. Shukla SK, Karow ME, Brady JM, Stemper ME, Kislow J, Moore N, Wroblewski K, Chyou PH, Warshauer DM, Reed KD, Lynfield R, Schwan WR: Virulence genes and genotypic associations in nasal carriage, communityassociated methicillin-susceptible and methicillin-resistant USA400 staphylococcus aureus isolates. J Clin Microbiol 2010, 48:3582-3592.

14. Amaral MM, Coelho LR, Flores RP, Souza RR, Silva-Carvalho MC, Teixeira LA, Ferreira-Carvalho BT, Figueiredo AM: The predominant variant of the Brazilian epidemic clonal complex of methicillin-resistant staphylococcus aureus has an enhanced ability to produce biofilm and to adhere to and invade airway epithelial cells. J Infect Dis 2005, 192:801-810.

15. Datta R, Huang SS: Risk of infection and death due to methicillin-resistant staphylococcus aureus in long-term carriers. Clin Infec Dis 2008, 47:176-181.

16. Sinha B, Herrmann M: Mechanism and consequences of invasion of endothelial cells by staphylococcus aureus. Thromb Haemost 2005, 94:266-277.

17. Merino N, Toledo-Arana A, Vergara-Irigaray M, Valle J, Solano C, Calvo E, Lopez JA, Foster TJ, Penadés JR, Lasa I: Protein a-mediated multicellular behavior in staphylococcus aureus. J Bacteriol 2009, 191:832-843.

18. Geoghegan JA, Corrigan RM, Gruszka DT, Speziale P, O'Gara JP, Potts JR, Foster TJ: Role of surface protein SasG in biofilm formation in stapylococcus aureus. J Bacteriol 2010, 192:5663-5673.

19. Houston P, Rowe SE, Pozzi C, Waters EM, O'Gara JP: Essential role for the major autolysin in the fibronectin-binding protein-mediated staphylococcus aureus biofilm phenotype. Infect Immun 2011, 79:1153-1165. 
20. Kiedrowski MR, Kavanaugh JS, Malone CL, Mootz JM, Voyich JM, Smeltzer MS, Bayles KW, Horswill AR: Nuclease modulates biofilm formation in community-associated methicillin-resistant staphylococcus aureus. PLoS One 2011, 6:e26714.

21. Bronner S, Monteil H, Prévost G: Regulation of virulence determinants in staphylococcus aureus: complexity and applications. FEMS Microbiol Rev 2004, 28:183-200.

22. Novick RP, Ross HF, Fiqueiredo AMS, Abramochkin G, Muir T: Activation and inhibition of staphylococcal Agr system. Science 2000, 287:391a.

23. Mayville $P$, Ji G, Beavis R, Yang H, Goger M, Novick RP, Muir TW: Structureactivity analysis of synthetic autoinducing thiolactone peptides from staphylococcus aureus responsible for virulence. Proc Natl Acad Sci USA 1999, 96:1218-1223.

24. Balaban N, Cirioni O, Giacometti A, Ghiselli R, Braunstein JB, Silvestri C, Mocchegiani F, Saba V, Scalise G: Treatment of staphylococcus aureus biofilm infection by the quorum-sensing inhibitor RIP. Antimicrob Agents Chemother 2007, 51:2226-2229.

25. Lopez-Leban F, Kiran MD, Wolcott R, Balaban N: Molecular mechanisms of RIP, an effective inhibitor of chronic infections. Int J Artif Organs 2010, 33:582-589.

26. Shenkman B, Varon D, Tamarin I, Dardik R, Peisachov M, Savion N, Rubinstein R: Role of agr (RNAIII) in staphylococcus aureus adherence to fibrinogen, fibronectin, platelets and endothelial cells under static and flow conditions. J Med Microbiol 2002, 51:747-754.

27. Coelho LR, Souza RR, Ferreira FA, Guimarães MA, Ferreira-Carvalho BT, Figueiredo AMS: agr RNAlll divergently regulates glucose-induced biofilm formation in clinical isolates of staphylococcus aureus. Microbiology 2008, 154:3480-3490.

28. Ferreira FA, Souza RR, Bonelli RR, Américo MA, Fracalanzza SEL, Figueiredo AMS: Comparison of in vitro and in vivo systems to study ica-independent staphylococcus aureus biofilm. J Microbiol Methods 2012, 88:393-398.

29. Zautner AE, Krause M, Stropahl G, Holtfreter S, Frickmann H, Maletzki C, Kreikemeyer B, Pau HW, Podbielski A: Intracellular persisting staphylococcus aureus is the major pathogen in recurrent tonsillitis. Plos One 2010, 5:e9452.

30. Trotonda MP, Tamber S, Memmi G, Cheung AL: MgrA represses biofilm formation in staphylococcus aureus. Infect Immun 2008, 76:5645-5654.

31. Kaito C, Saito Y, Nagano G, Ikuo M, Omae Y, Hanada Y, Han X, Kuwahara-Arai K, Hishinuma T, Baba T, Ito T, Hiramatsu K, Sekimizu K: Transcription and translation products of the cytolysin gene psm-mec on the mobile genetic element SCCmec regulate staphylococcus aureus regulation. PLoS Pathog 2011, 7:e1001267.

32. Joshi SG, Paff M, Friedman G, Fridman G, Fridman A, Brooks AD: Control of methicillin-resistant staphylococcus aureus planktonic form and biofilms: a biocidal efficacy study of nonthermal dielectric-barrier discharge plasma. Am J Infect Control 2010, 38:293-301.

33. O’Neill E, Pozzi C, Houston P, Humphreys H, Robinson DA, Loughman A, Foster TJ, O'Gara JP: A novel staphylococcus aureus biofilm phenotype mediated by the fibronectin-binding proteins, FnBPA and FnBPB. J Bacteriol 2008, 190:3835-3850.

34. Vergara-Irigaray M, Valle J, Merino N, Latasa C, García B, Ruiz de Los Mozos I, Solano C, Toledo-Arana A, Penadés JR, Lasa I: Relevant role of fibronectinbinding proteins in staphylococcus aureus biofilm-associated foreign-body infections. Infect Immun 2009, 77:3978-3991.

35. Lauderdale KJ, Boles BR, Cheung AL, Horswill AR: Interconnections between sigma B, agr, and proteolytic activity in staphylococcus aureus biofilm maturation. Infect Immun 2009, 7:1623-1635

36. Wolz C, Pöhlmann-Dietze P, Steinhuber A, Chien YT, Manna A, van Wamel W, Cheung A: Agr-independent regulation of fibronectin-binding protein (s) by the regulatory locus sar in staphylococcus aureus. Mol Microbiol 2000, 36:230-243.

37. Bartlett AH, Foster TJ, Hayashida A, Park PW: Alpha-toxin facilitates the generation of CXC chemokine gradients and stimulates neutrophil homing in Staphylococcus aureus pneumonia. J Infect Dis 2008, 198:1529-1535.

38. Bubeck Wardenburg J, Bae T, Otto M, DeLeo FR, Schneewind O: Poring over pores: alpha-hemolysin and Panton-valentine leukocidin in staphylococcus aureus pneumonia. Nat Med 2007, 13:1405-1406.

39. Wang R, Braughton KR, Kretschmer D, Bach TH, Queck SY, Li M, Kennedy AD, Dorward DW, Klebanoff SJ, Peschel A, DeLeo FR, Otto M: Identification of novel cytolytic peptides as key virulence determinants for community-associated MRSA. Nat Med 2007, 13:1510-1514.
40. Wright JS 3rd, Jin R, Novick RP: Transient interference with staphylococcal quorum sensing blocks abscess formation. Proc Natl Acad Sci USA 2005, 102:1691-1696.

41. Traber KE, Lee E, Benson S, Corrigan R, Cantera M, Shopsin B, Novick RP: agr function in clinical staphylococcus aureus isolates. Microbiology 2008, 154:2265-2274.

42. Park SY, Chong YP, Park HJ, Park KH, Moon SM, Jeong JY, Kim MN, Kim SH, Lee SO, Choi SH, Woo JH, Kim YS: agr dysfunction and persistent methicillin-resistant staphylococcus aureus bacteremia in patients with removed eradicable foci. Infection 2013, 41:111-119.

43. Falkow S: Bacterial entry into eukaryotic cells. Cell 1991, 65:1099-1102.

44. Garzoni C, François P, Huyghe A, Couzinet S, Tapparel C, Charbonnier Y, Renzoni A, Lucchini S, Lew DP, Vaudaux P, Kelley WL, Schrenzel J: A global view of staphylococcus aureus whole genome expression upon internalization in human epithelial cells. BMC Genomics 2007, 8:171.

45. Wesson CA, Liou LE, Todd KM, Bohach GA, Trumble WR, Bayles KW: Staphylococcus aureus Agr and Sar global regulators influence internalization and induction of apoptosis. Infect Immun 1998, 66:5238-5243.

46. Pozzi C, Waters EM, Rudkin JK, Schaeffer CR, Lohan AJ, Tong P, Loftus BJ, Pier GB, Fey PD, Massey RC, O'Gara JP: Methicillin resistance alters the biofilm phenotype and attenuates virulence in staphylococcus aureus device-associated infections. PLoS Pathog 2012, 8:e1002626.

47. Rudkin JK, Edwards AM, Bowden MG, Brown EL, Pozzi C, Waters EM, Chan WC, Williams P, O'Gara JP, Massey RC: Methicillin resistance reduces the virulence of healthcare-associated methicillin-resistant staphylococcus aureus by interfering with the agr quorum sensing system. J Infect Dis 2012, 205:798-806.

48. Morfeldt E, Tegmark K, Arvidson S: Transcriptional control of the agrdependent virulence gene regulator, RNAlll, in staphylococcus aureus. Mol Microbiol 1996, 21:1227-1237.

49. Beenken KE, Mrak LN, Griffin LM, Zielinska AK, Shaw LN, Rice KC, Horswill AR, Bayles KW, Smeltzer MS: Epistatic relationships between sarA and agr in staphylococcus aureus biofilm formation. PLoS One 2010, 5:e10790.

50. CLSI: Methods for dilution antimicrobial susceptibility tests for bacteria that grow aerobically; approved standard. 9th edition. Wayne, PA: CLSI document M07-A9. Clinical and Laboratory Standards Institute; 2012.

51. De Jonge BLM, De Lencastre $H$, Tomasz A: Supression of autolysis and cell wall turnover in heterogeneous Tn551 mutants of a methicillin-resistant staphylococcus aureus strain. J Bacteriology 1991, 173:1105-1110.

52. Adhikari RP, Arvidson S, Novick RP: A nonsense mutation in agrA accounts for the defect in agr expression and the avirulence of staphylococcus 8325-4 traP::kan. Infect Immun 2007, 75:4534-4540.

53. Li M, Cheung GYC, Hu J, Wang D, Joo H, De Leo FR, Otto M: Comparative analysis of virulence and toxin expression of global community-associated MRSA strains. J Infect Dis 2010, 202:1866-1876.

54. Oliveira DC, de Lencastre $H$ : Multiplex PCR strategy for rapid identification of structural types and variants of the mec element in methicillin-resistant staphylococcus aureus. Antimicrob Agents Chemother 2002, 46:2155-2161.

55. Dunn OJ: Basic statistics: a primer for the biomedical sciences. New York: John Wiley \& Sons; 1964.

doi:10.1186/1471-2180-13-93

Cite this article as: Ferreira et al:: Impact of agr dysfunction on virulence profiles and infections associated with a novel methicillin-resistant Staphylococcus aureus (MRSA) variant of the lineage ST1-SCCmec IV. BMC Microbiology 2013 13:93. 